\title{
EVALUATION OF CURCUMIN AND CHITOSAN PROTECTIVE EFFECT ON SUBMANDIBULAR SALIVARY GLAND TOXICITY INDUCED BY MONOSODIUM GLUTAMATE IN MALE ALBINO RATS
}

\author{
Asmaa S. Elgamal*
}

\begin{abstract}
Monosodium glutamate is a well-known food flavor additives that is widely used all over the world but its chronic intake leads to many reported side effects.

Objectives : The goal of this study was to evaluate the prophylactic role of chitosan and curcumine extract, as a well-known antioxidant, against the submandibular salivary gland (SMG) damage induced by chronic intake of monosodium glutamate (MSG).

Material and methods: 36 adult male Albino rats were randomly divided into 4 groups; Group 1 (control) group, group 2 (MSG group): rats received a daily dose of MSG only by oral gavage, group 3 ( MSG + Chitosan treated group): rats received a daily dose of MSG + chitosan and finally group 4 ( MSG + curcumin treated group): rats received a daily dose of MSG + curcumin. After 6 weeks, the submandibular salivary glands were excised and processed for histological and caspase 3 immunohistochemical examination.
\end{abstract}

Results: histological examination by H\&E stain of group 3 and 4 revealed improvement of secretory portion architecture in addition to decreased vaculation and pleomorphism than group 2 . There were a high statistical significant difference of caspase 3 immuno-expression between the treated chitosan and curcumin groups (group3 and 4) and MSG group (group 2) as p values were 0.005 and 0.017 respectively.

Conclusion: administration of chitosan or curcumin has a protective effect on SMG toxicity induced by chronic intake of MSG.

KEY WORDS: monosodium glutamate toxicity, curcumin extract, chitosan and submandibular salivary gland.

\footnotetext{
* Lecturer, Oral Biology Department, Faculty of Dentistry, Beni-Suef University, Egypt.
} 


\section{INTRODUCTION}

Monosodium glutamate (MSG) is a flavor enhancer widely used in the food industry all over the world; it is present at solid crystals form in most open market. It is the sodium salt of glutamic acid (GA) containing $78 \%$ of glutamic acid, $22 \%$ of sodium ${ }^{[1]}$. Its obesogenic properties have been studied by many authors ${ }^{[2][3]}$. It is also associated with insulin resistance ${ }^{[4]}$ and hyperinsulinemia ${ }^{[5]}$. At the systemic level, the harmful effect of MSG has been reported in several structures, as central nervous system, liver, fatty tissues, digestive tract and cardiovascular system ${ }^{[6][7]}$. Its chronic intake of MSG causes oxidative damage and decreased levels of antioxidant enzymes resulting in impairment in kidney, liver and brain functions ${ }^{[8]}$. It has been also reported that long term administration of MSG to albino rats showed neoplastic changes in parotid salivary gland ${ }^{[2]}$.

Oxidative stress is a state of imbalance between generation of reactive oxygen species and levels of antioxidant defense system. It plays an important role in the chronic complications of many diseases. Antioxidants constitute the foremost defense system that limit the toxicity associated with free radicals ${ }^{[9]}$. Organisms have evolved a wide range of endogenous antioxidant defenses to balance the physiological generation of free radicals. But in case of increased free radical generation the reinforcement of endogenous antioxidants with natural dietary antioxidants may be essential to decrease the cumulative effects of oxidatively damaged molecules ${ }^{[10]}$.

Curcumin is an important constituent of the plant Curcuma longa roots which is a member of the family (Zingiberaceae). It is used as a spice to give specific flavor and yellow color to food ${ }^{[10]}$.

Curcumin, has received attention as a promising natural dietary supplement for protection against many diseases. it was found to exhibit a variety of biological activities including antitumor [11], antioxidant [12], anti-inflammatory properties and antiviral activities ${ }^{[13]}$. The protective effects of curcumin against hazardous chemicals were studied in different animals ${ }^{[14,15]}$. Hepatoprotective, antimutagenic, oxidative and anticarcinogenic effect of curcumin have been also investigated by Premkumar ${ }^{[16]}$.

Chitosan is a natural polymer, derived from shrimp and lobster shells, with excellent properties such as biocompatibility, biodegradability, non-toxicity and adsorptive abilities. Because of its indigestibility by digestive enzymes, chitosan is classified as a dietary fiber ${ }^{[17]}$. Chitosan has many biological activities as antioxidant ${ }^{[18]}$, antitumor features in human liver ${ }^{[19]}$ and free radical scavenging activity in vivo and ex vivo ${ }^{[20,21]}$, antihypertensive, chemopreventive and immuno-potentiating ${ }^{[22]}$ in addition to antimicrobial and antiviral activity ${ }^{[20]}$.

Therefore, the aim of the present study was to assess the possible protective effects of curcumin and chitosan on the submandibular salivary gland toxicity induced by monosodium glutamate and to compare between them histologically and immunohistochemically.

\section{MATERIALS AND METHODS}

\section{Materials used}

a) Monosodium Glutamate preparation: the chemical used was Monosodium glutamate salt (C5H9NO4.-Na) Purity 99\% NT. A stock solution was prepared by dissolving $3 \mathrm{~g}$ of MSG crystals in $100 \mathrm{ml}$ of distilled water to obtain a concentration of $30 \mathrm{mg} / \mathrm{ml}$. then, oral doses of $30 \mathrm{mg} / \mathrm{kg} /$ day were given to the rats according to their weights ${ }^{[23]}$.

b) Curcumin Extract preparation: high purity curcumin powder was purchased from BIO 
BASIC INC. it was dissolved in distilled water by a concentration of $30 \mathrm{mg} / \mathrm{ml}$. doses of $30 \mathrm{mg} /$ $\mathrm{kg}$ /day were orally given to the rats ${ }^{[24]}$.

c) Chitosan preparation: high molecular weight chitosan was obtained from LOBA CHEMIE PVT. LTD. $15 \mathrm{gm}$ was dissolved in $100 \mathrm{ml}$ of $3 \%$ diluted acetic acid ${ }^{[25]}$ to obtain a viscous solution with concentration of $15 \mathrm{mg} / \mathrm{ml}$. then oral doses of $30 \mathrm{mg} / \mathrm{kg}$ /day were given orally to the rats.

\section{Experimental design}

36 adult male Albino rats weighing between 200 $-250 \mathrm{gm}$ were obtained and bred at animal house of Nahda University. The rats kept in separate stainless steel cages under good ventilation and kept in the laboratory under constant conditions of temperature $\left(24 \pm 2^{\circ} \mathrm{C}\right)$ and $\left(50 \pm 5^{\circ} \%\right)$ humidity for at least one week before the experiment. After the acclimatization period, the animals were divided into 4 groups ( 9 rats in each gr.):

- Group 1: rats were kept under normal condition and received $2 \mathrm{ml}$ of distilled water orally once daily and considered as control group.

- Group 2: (MSG group) rats were received 30 $\mathrm{mg} / \mathrm{kg} /$ day of MSG by oral gavage.

- Group 3: (MSG + chitosan treated group) rats were received $30 \mathrm{mg} / \mathrm{kg}$ / day of $\mathrm{MSG}+30 \mathrm{mg} /$ $\mathrm{kg} /$ day of chitosan by oral gavage.

- Group 4: (MSG +curcumin treated group) rats were received $30 \mathrm{mg} / \mathrm{kg}$ / day of MSG $+30 \mathrm{mg}$ / $\mathrm{kg}$ /day of curcumin by oral gavage.

At the end of the study period (6 weeks), all rats were anesthetized and scarified by cervical dislocation; submandibular salivary glands (SMG) of both sides were excised and processed for:

- Routine histological examination by hematoxylin and eosin (H \& E).
- Immunohistochemical examination by using avidin-biotin technique for Caspase 3 immuno stain.

\section{Immunohistochemical statistical analysis:}

$1^{\text {st }}$, the histological sections were examined by light microscope to evaluate the incidence of positive reactions. Positive Caspase-3-labelled cells were determined by brown cytoplasmic staining. Then, digital image analysis was performed using image-j software to calculate the mean and area percentage of $+v e$ cytoplasmic immunoreaction in 5 different fields for each specimen. Finally, all data were tabulated and analyzed statistically using SPSS (statistical package for social sciences) software version 19.0 for Windows to calculate the mean and standard deviation for each group. The statistical significance between all groups were calculated using paired sample T test; a probability value ( $\mathrm{p}$ value) less than 0.05 was considered statistically significant.

\section{RESULTS}

\section{Histological results}

\section{Group 1}

Examination of the control group showed normal architecture of the submandibular salivary gland (SMG) with predominantly serous acini. It consisted of seromucous acini, intercalated, striated, excretory ducts and granular convoluted tubules (GCTs; is a segment of the duct system of all rodents, situated between the striated and intercalated duct). in addition to connective tissue stroma. The serous acini were regular in shape with a narrow lumen having pyramidal cells with basophilic cytoplasm and rounded basally located nuclei. On the other hand, mucous acini composed of flattened cells having clear cytoplasm and basally flattened nuclei surrounding a wide lumen. The intercalated ducts have low cuboidal cells with basophilic 
cytoplasm and centrally situated rounded nuclei. The GCTs revealed tall columnar cell lining having large rounded basally located nuclei and filled with apical eosinophilic excretory granules. The striated ducts revealed columnar cells lining with centrally located rounded nuclei and extensively eosinophilic cytoplasm with characteristics basal striations. While the excretory ducts were lined by pseudostratified columnar epithelium and located in c.t. stroma adjacent to variable sized blood vessels (Fig. 1A, 2A and 3A).

\section{Group 2:}

SMG examination of monosodium glutamate group revealed loss of normal glandular architecture. Irregular shape of serous acini with indistinct boundaries and acinar fusion were observed, Some acini showed vacuolated cytoplasm. Nuclear pleomorphism, hyperchromatism with increased nuclear cytoplasmic ratio and abnormal mitotic figures were clearly appeared in the acinar and duct cells. Some striated duct and GCTs showed degeneration with ill-defined borders. Excretory
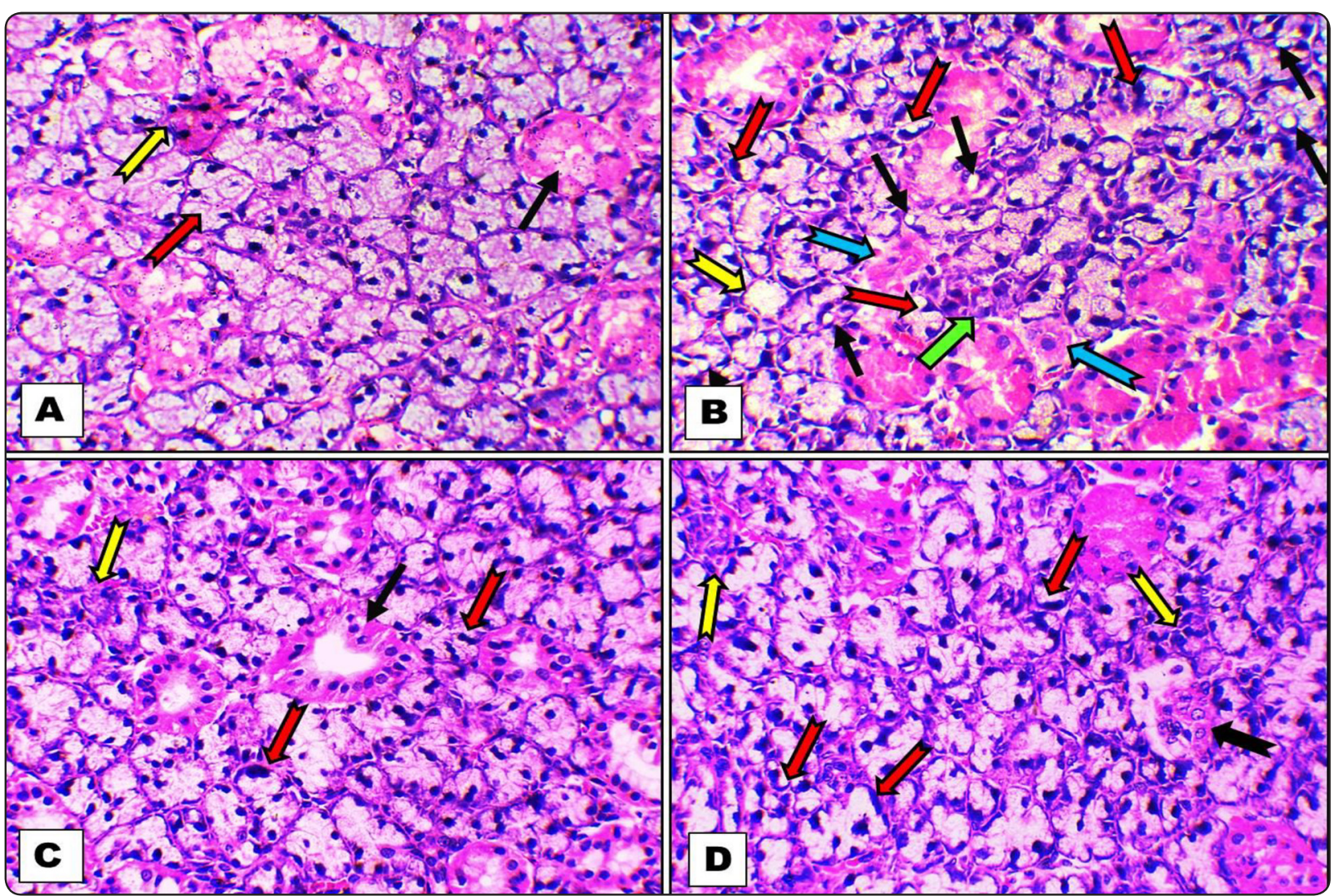

Fig. (1): A photomicrograph of SMG serous acini of all examined groups: (A) group 1;Normal architecture of serous acini (red arrow) with duct system composed of intercalated ducts (yellow arrow), granular convoluted tubules (black arrow). (B) group 2; Lose of normal arrangement of serous acini with ill-defined margins, Loss of acinar outline(green arrow), vacuolated cytoplasm (black arrow), nuclear pleomorphism (red arrow), ducts undergoing degeneration with ill-defined borders (notched blue arrow) and degenerated acinus leaving large vacuole (yellow arrow). (C) group 3; striated duct (black arrow), more arranged acini than gr. 2 with less apparent nuclear pleomorphism (red arrow) and Loss of acinar outline(yellow arrow). (D) group 4; marked nuclear pleomorphism (red arrow), degenerated duct (notched black arrow) and acinar fusion (notched yellow arrow) (H\&E x400). 
ducts became dilated. Mucous acini became irregular in shape and acinar fusion appeared in some areas. Also, striated ducts showed nuclear pleomorphism, ill-defined cell borders and distortion of basal striation. Blood vessels were congested (Fig. 1B, $2 \mathrm{~B}$ and $3 \mathrm{~B})$.

\section{Group 3:}

SMG examination of chitosan treated group showed significant improvement in acinar and duct cells compared to the monosodium glutamate group. The acini returned their uniformity and regularly structured, striated ducts returned their basal striation and other ducts showed normal architecture and proper alignment. Also, the nuclear pleomorphism decreased significantly (Fig. 1C, 2C). Mucous acini also revealed improvement in their shape and arrangement (3C).

\section{Group 4:}

Examination of curcumin treated group showed also improvement in glandular architecture compared to group 1. The nuclear pleomorphism decreased to some extent, vacuolated cytoplasm
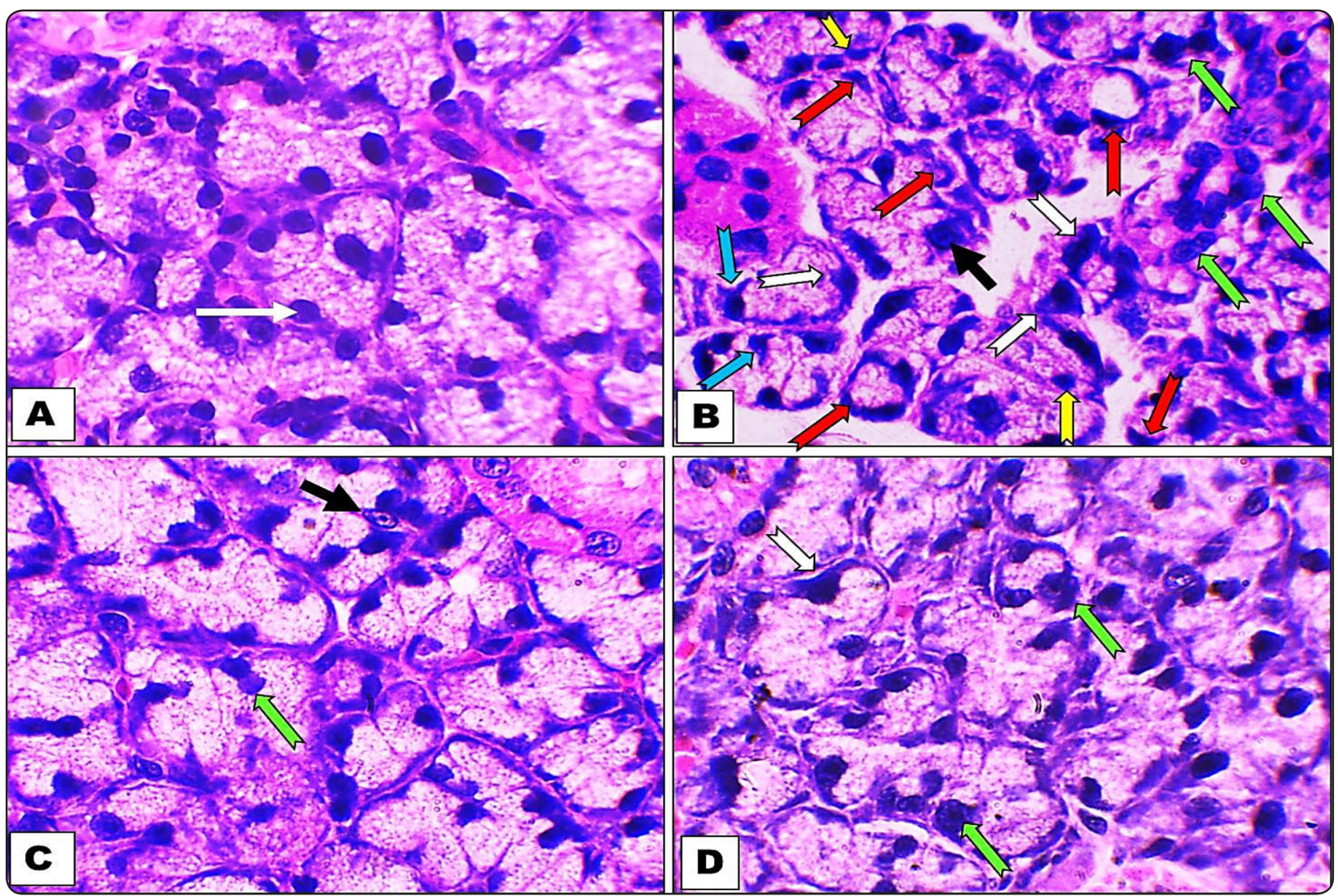

Fig. (2): A photomicrograph of SMG showing the nuclear shape of all examined groups: (A) Group 1; Normal rounded nucleus of the serous acini (white arrow). (B) pleomorphism in Group 2 in the form of; crescent shaped nucleus (red arrow), large irregular shaped hyperchromatic eccentric nucleus (white arrow), prominent nucleolus (black arrow), pyknotic nuclei (yellow arrow), abnormal mitotic figures (blue arrow) and asymmetrical mitosis (green arrow). (C) Group 3; prominent nucleolus (black arrow), nucleus doubling (green arrow). (D) Group 4; large irregular shaped hyperchromatic eccentric nucleus (white arrow) and giant nucleus (green arrow) (H\&E x1000). 


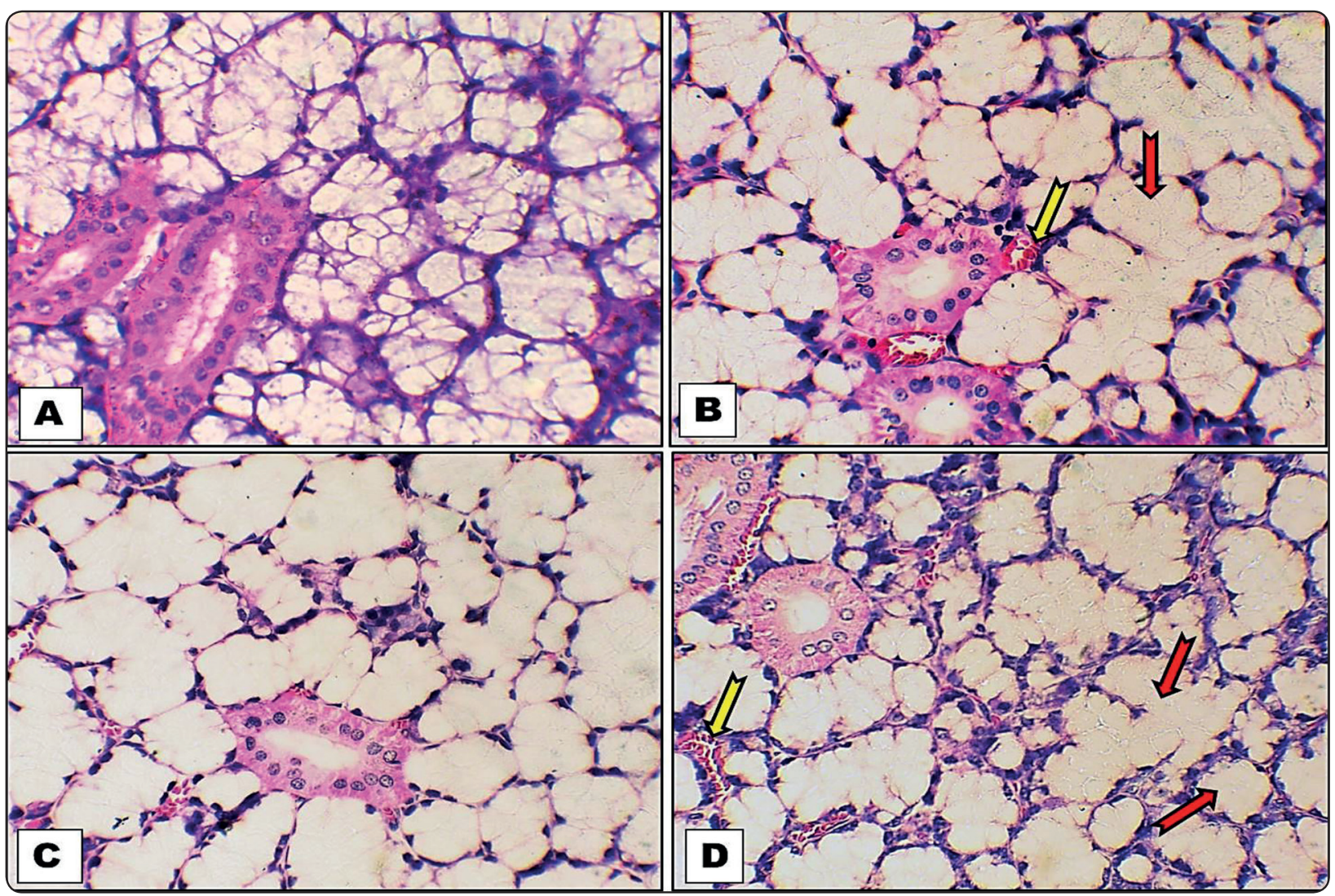

Fig. (3): A photomicrograph of SMG mucous acini showing: (A) Group 1; regularly arranged mucous acini. (B) Group 2; acinar fusion (red arrow) and congested blood vessels (yellow arrow). (C)Group 3; regular shaped acini (D) Group 4; ;acinar fusion (red arrow) and congested blood vessels (yellow arrow) (H\&E x400).

disappeared and acinar fusion decreased (Fig. 1D, $2 \mathrm{D}$ and $3 \mathrm{D})$.

\section{Immunohistochemical results:}

Immunohistochemical examination using caspase-3 antibodies of SMG of group 1 showed negative to mild caspase- 3 immunoreactivity in the secretory portion and mild +ve reaction in the ductal cells; the image analysis revealed that $9.06 \%$ of the specimen surface area gave positive reaction. On the other hand, group 2 showed strong nuclear and cytoplasmic reaction of caspase- 3 immunoreactivity in the acinar and duct cells $(28.74 \%)$. The treated groups 3 and 4 showed mild Immuno-reactivity caspases- 3 in the acinar cells and moderate reaction in the duct cells (12.85\% and $14.19 \%$ respectively) (Fig. 4 and 5). the improvement of the chitosan and curcumin treated groups were observed especially in chitosan group (group 3) as there was a statistical significant difference between the treated groups 3 , 4 and the untreated group 2 ( 0.005 and $0.017 \mathrm{p}$ value respectively). In addition there was no statistical significant difference between the control group and chitosan group (0.062 p value) (table 1 ) 

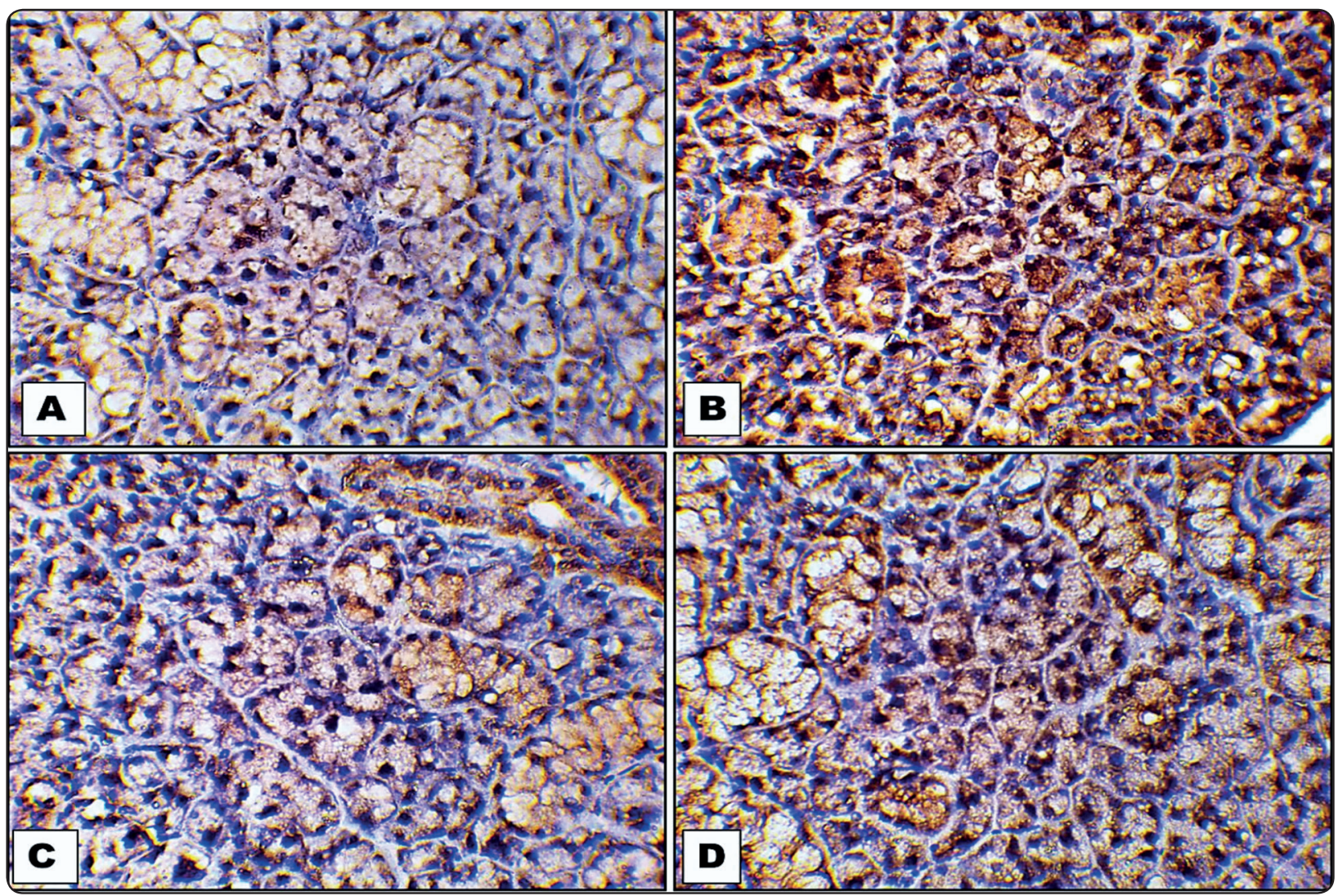

Fig. (4): A photomicrograph of SMG showing caspase-3 Immunohistochemical reaction for all examined groups; A: group 1, B: group 2, C: group 3, D: group 4 (caspase 3 X 400)

TABLE (1): paired sample $t$ test comparing between caspase 3 immuno-expression in all groups. (the difference is considered statistically significant if $\mathrm{p}$ value is less than 0.05 ).

\begin{tabular}{|c|c|c|c|c|c|c|c|c|c|}
\hline \multicolumn{10}{|c|}{ Paired Samples Test } \\
\hline & & \multicolumn{5}{|c|}{ Paired Differences } & \multirow[b]{3}{*}{$\mathrm{t}$} & \multirow[b]{3}{*}{ df } & \multirow{3}{*}{$\begin{array}{c}\text { Sig. } \\
\text { (2-tailed) }\end{array}$} \\
\hline & & \multirow[b]{2}{*}{ Mean } & \multirow{2}{*}{$\begin{array}{c}\text { Std. } \\
\text { Deviation }\end{array}$} & \multirow{2}{*}{$\begin{array}{l}\text { Std. Error } \\
\text { Mean }\end{array}$} & \multicolumn{2}{|c|}{$\begin{array}{l}95 \% \text { Confidence Interval } \\
\text { of the Difference }\end{array}$} & & & \\
\hline & & & & & Lower & Upper & & & \\
\hline Pair 1 & gr.1 - gr.2 & -96.46040 & 32.83667 & 14.68500 & -137.23251 & -55.68829 & -6.569 & 8 & .003 \\
\hline Pair 2 & gr.1 - gr.3 & -12.90920 & 11.25515 & 5.03346 & -26.88431 & 1.06591 & -2.565 & 8 & .062 \\
\hline Pair 3 & gr.1 - gr.4 & -30.69880 & 15.23291 & 6.81236 & -49.61296 & -11.78464 & -4.506 & 8 & .011 \\
\hline Pair 4 & gr.2 - gr.3 & 83.55120 & 33.23098 & 14.86135 & 42.28948 & 124.81292 & 5.622 & 8 & .005 \\
\hline Pair 5 & gr.2 - gr.4 & 65.76160 & 37.35213 & 16.70438 & 19.38280 & 112.14040 & 3.937 & 8 & .017 \\
\hline Pair 6 & gr.3 - gr.4 & -17.78960 & 14.75042 & 6.59659 & -36.10467 & .52547 & -2.697 & 8 & .054 \\
\hline
\end{tabular}




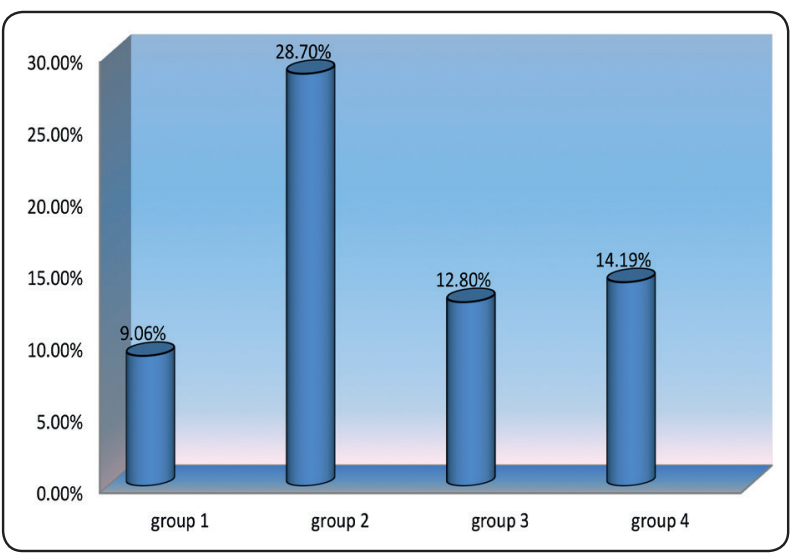

Fig (5): graph showing the surface area percentage of $+v e$ caspase 3 immuno-expression in each group

\section{DISCUSSION}

Monosodium glutamate (MSG) is the sodium salt of glutamic acid and the most applied food additives used as a food flavor enhancer all over the world ${ }^{[26,27]}$. On the other hand, many previous studies reported its hazards and toxic effects on human and animals including allergic reaction; flushing, sweating, weakness, numbness, dizziness and headache in addition to increase the appetite and subsequently weight gain ${ }^{[4,28]}$. Many authors approved the cytotoxic effect of MSG on different organs as Ortiz et al. ${ }^{[29]}$ who investigated its effect on liver and kidney and Sakr \& Badawy ${ }^{[30]}$ who investigated its effect on male rat reproductive system. Roa \& del ${ }^{[31]}$ also found that exposure to MSG caused morphofunctional alterations at the parotid level represented by reduction in the volume of the gland, changes in the adenomere and striated ducts in the gland. in addition, it decreased $\mathrm{pH}$ levels and salivary flow, increased a-amylase enzyme and changed the percentages of salivary elements.

In the present study we used a dose of $30 \mathrm{~m} /$ $\mathrm{kg}$ every day of MSG that was approved to cause salivary gland toxicity ${ }^{[2][1]}$. This toxicity was manifested histologically by loss of serous acini normal arrangement with ill-defined margins and acinar fusionin addition to nuclear changes in the form of large hyperchromatic, pleomorphic and some pyknotic nuclei. Intercalated and striated ducts were dilated with ill-defined cell borders. These findings were in agreement with some authors who investigated the effect of MSG on the submandibular salivary gland as El Imam and Adb El salam ${ }^{[1]}$ and Mahmoud et. al. ${ }^{[32]}$, parotid salivary gland as Mubarak et al. ${ }^{[2]}$ and subligual salivary gland as Shredah\& Nagy ${ }^{[33]}$. Some author regarded the cytotoxic effect of MSG to its ability to generate reactive oxygen species (ROS) and to decrease the antioxidant enzymes activity as superoxide dismutase activity (SOD) and glutathione metabolizing enzymes ${ }^{[34]}$.

It was noticed that chitosan in the present study decreased the cytotoxic effect of MSG on SMG as it decreased vaculation, acinar changes and nuclear pleomorphism and that was confirmed by decreased caspase 3 immunoexpression which was statistically significant than group 2 and non-significant to control group 1 . These finding exactly coincided with Mahmoud et al. ${ }^{[32]}$ who investigated the effect of nanochitosan on the cytotoxicity of MSG on salivary gland with differences in the dose and duration of the experiment. Many authors tried to explain the curative effect of Chitosan; some found that it can regulate innate and adaptive immune responses. As it has the ability of stimulating the immune response against tumors and using it as an adjuvant in the preparation of various vaccines was reported ${ }^{[35,36]}$.

Nam et al. ${ }^{[22]}$ examined chemo-preventive effects of hydrolyzed form of chitosan; chitosan oligosaccharide (COS) on colon cancer cells and reported that $\mathrm{COS}$ exerts its chemopreventive effect by increasing the level of antioxidant enzymes, as quinone reductase $(\mathrm{QR})$, glutathione S-transferase (GST ) and GSH, and by inhibiting renal ornithine decarboxylase (ODC) activity and COX-2 expression in vitro. Quan et al. ${ }^{[37]}$ also have discovered that COS have antiangiogenic activity and they regarded its effect due to inhibition of heparenase enzyme. 
In the present study it was observed that coadministration of curcumin with MSG also led to decreasing the acinar changes and the degree of pleomorphism in SMG. That was confirmed by presence of statistical significant difference of caspase 3 immunoexpression between the curcumin treated group andMSG group. These results coincides with Sakr \& Badawy ${ }^{[30]}$ study; as they found that co-administration of curcumin to MSG-treated rats improved the histopathological alterations induced by MSG in rat reproductive system. Walvekar et al. ${ }^{[24]}$ also found that the curcumin was effective antioxidant that can protect mice SMG cells from free radicals induced oxidative stress.

It is well known that MSG exerts its cytotoxic effect due to production of oxygen free radicals and oxidative stress in different tissues of experimental animals $^{[38,39]}$. Some authors attributed the protective effect of curcumin to its free radical scavenging activity ability, as it significantly reduced the levels of these free radicals, and induction of detoxification enzymes ${ }^{[40]}$. Chan and $\mathrm{Yu}{ }^{[41]}$ also stated that curcumin exerted a good ability to scavenge oxygen free radicals and could protect DNA from damage.

Some authors reported that protective effect of curcumin was due to its ability to protect against mitochondrial injury and to inhibit apoptosis by inhibition the intrinsic apoptotic pathway ${ }^{[42]}$ and other authors have reported that it is effective in reducing the dysregulation of the cellular redox balance ${ }^{[43]}$.

\section{CONCLUSION}

Within the extent of this study, it was concluded that both chitosan and curcumin have a protective effect on the submandibular salivary gland against the cytotoxic effect of chronic intake of monosodium glutamate salt.

\section{REFERENCES}

1. El Imam,H. F., \& Abd El Salam, N. N. (2019). Histological and Ultra structural Study of the Effect of Monosodium Glutamate on the Submandibular Salivary Gland of Adult Albino Rats. Egyptian Dental Journal, 65(1-January (Oral Medicine, X-Ray, Oral Biology \& Oral Pathology)), 319329.

2. HS, M., El-Bolok, A. H., \& Refaai, R. A. (2015). Histological and immunohistochemical evaluation of the effect of monosodium glutamate on parotid salivary glands of adult male albino rats. DENTAL JOURNAL, 61(4557), 4565 .

3. Miranda, R. A., da Silva Franco, C. C., de Oliveira, J. C., Barella, L. F., Tófolo, L. P., Ribeiro, T. A., ... \& Vieira, E. (2017). Cross-fostering reduces obesity induced by early exposure to monosodium glutamate in male rats. Endocrine, 55(1), 101-112.

4. Insawang, T., Selmi, C., Cha'on, U., Pethlert, S., Yongvanit, P., Areejitranusorn, P., \& Hammock, B. D. (2012). Monosodium glutamate (MSG) intake is associated with the prevalence of metabolic syndrome in a rural Thai population. Nutrition \& Metabolism, 9(1), 50.

5. Marmo, M. R., Dolnikoff, M. S., Kettelhut, I. C., Matsushita, D. M., Hell, N. S., \& Lima, F. B. (1994). Neonatal monosodium glutamate treatment increases epididymal adipose tissue sensitivity to insulin in threemonth old rats. Brazilian journal of medical and biological research $=$ Revista brasileira de pesquisas medicas $\mathrm{e}$ biologicas, 27(5), 1249-1253.

6. Collison, K. S., Maqbool, Z. M., Inglis, A. L., Makhoul, N. J., Saleh, S. M., Bakheet, R. H., ... \& Al-Mohanna, F. A. (2010). Effect of dietary monosodium glutamate on HFCS-induced hepatic steatosis: expression profiles in the liver and visceral fat. Obesity, 18(6), 1122-1134.

7. López-Miranda, V., Soto-Montenegro, M. L., UrangaOcio, J. A., Vera, G., Herradón, E., González, C., ... \& Abalo, R. (2015). Effects of chronic dietary exposure to monosodium glutamate on feeding behavior, adiposity, gastrointestinal motility, and cardiovascular function in healthy adult rats. Neurogastroenterology \& Motility, 27(11), 1559-1570.

8. Shivasharan, B. D., Nagakannan, P., Thippeswamy, B. S., \& Veerapur, V. P. (2013). Protective effect of Calendula officinalis L. flowers against monosodium glutamate induced oxidative stress and excitotoxic brain damage 
in rats. Indian Journal of Clinical Biochemistry, 28(3), 292-298.

9. Topdag, S., Aslaner, A., Tataroglu, C., \& Ilce, Z. (2005). Evaluation of antioxidant capacity in lung carcinoma. Indian Journal of Thoracic and Cardiovascular Surgery, 21(4), 269-271.

10. Krishnaiah, D., Sarbatly, R., \& Bono, A. (2007). Phytochemical antioxidants for health and medicine a move towards nature. Biotechnology and Molecular Biology Reviews, 2(4), 97-104.

11. Ströfer, M., Jelkmann, W., \& Depping, R. (2011). Curcumin decreases survival of Hep3B liver and MCF7 breast cancer cells. Strahlentherapie und Onkologie, 187(7), 393-400.

12. Venkatesan, N., \& Chandrakasan, G. (1995). Modulation of cyclophosphamide-induced early lung injury by curcumin, an anti-inflammatory antioxidant. Molecular and cellular biochemistry, 142(1), 79-87.

13. Mazumder, A., Raghavan, K., Weinstein, J., Kohn, K. W., \& Pommier, Y. (1995). Inhibition of human immunodeficiency virus type-1 integrase by curcumin. Biochemical pharmacology, 49(8), 1165-1170.

14. Tirkey, N., Kaur, G., Vij, G., \& Chopra, K. (2005). Curcumin, a diferuloylmethane, attenuates cyclosporineinduced renal dysfunction and oxidative stress in rat kidneys. BMC pharmacology, 5(1), 15.

15. Mathuria, N. E. E. T. A., \& Verma, R. J. (2007). Curcumin ameliorates aflatoxin-induced lipid peroxidation in liver, kidney and testis of mice-an in vitro study. Acta Pol Pharm, 64(5), 413-416.

16. Premkumar, K., Kavitha, S., Santhiya, S. T., \& Ramesh, A. (2004). Interactive effects of saffron with garlic and curcumin against cyclophosphamide induced genotoxicity in mice. Asia Pacific Journal of Clinical Nutrition, 13(3).

17. Kohda, N., Inoue, S., Noda, T., \& Saito, T. (2012). Effects of a chitosan intake on the fecal excretion of dioxins and fat in rats. Bioscience, biotechnology, and biochemistry, 120300 .

18. Ai, H., Wang, F., Xia, Y., Chen, X., \& Lei, C. (2012). Antioxidant, antifungal and antiviral activities of chitosan from the larvae of housefly, Musca domestica L. Food chemistry, 132(1), 493-498.

19. Jadhav, S. D., \& Singh, A. (2017). Oxidative Annulations Involving DMSO and Formamide: K2S2O8 Mediated
Syntheses of Quinolines and Pyrimidines. Organic letters, 19(20), 5673-5676.

20. Je, J. Y., Park, P. J., \& Kim, S. K. (2004). Free radical scavenging properties of hetero-chitooligosaccharides using an ESR spectroscopy. Food and Chemical Toxicology, 42(3), 381-387.

21. Huang, R., Mendis, E., \& Kim, S. K. (2005). Factors affecting the free radical scavenging behavior of chitosan sulfate. International journal of biological macromolecules, 36(1-2), 120-127.

22. Nam, K. S., Kim, M. K., \& Shon, Y. H. (2007). Chemopreventive effect of chitosan oligosaccharide against colon carcinogenesis. Journal of microbiology and biotechnology, 17(9), 1546-1549.

23. Leshchenko, I. V., Shevchuk, V. H., Falalieieva, T. M., \& Beregova, T. V. (2012). The influence of long-term monosodium glutamate feeding on the structure of rats pancreas. Fiziolohichnyi Zhurnal (Kiev, Ukraine: 1994), 58(2), 59-65.

24. Walvekar, M. V., Sarvalkar, P. P., \& Pol, S. B. (2012). Effect of curcumin supplementation on the submandibular salivary glands of D-galactose induced male mice. International Journal of Pharmaceutical Sciences and Research, 3(12), 4796.

25. Guan, G., Wang, H., Peng, H., \& Li, G. (2016). Low dosage of chitosan supplementation improves intestinal permeability and impairs barrier function in mice. BioMed research international, 2016.

26. Garattini, S. (2000). Glutamic acid, twenty years later. The Journal of nutrition, 130(4), 901S-909S.

27. Pavlovic, V., Pavlovic, D., Kocic, G., Sokolovic, D., Sarac, M., \& Jovic, Z. (2009). Ascorbic acid modulates monosodium glutamate induced cytotoxicity in rat thymus. Bratislavské lekarske listy, 110(4), 205.

28. Manal Said, T., \& Nawal, A. B. (2012). Adverse effects of monosodium glutamate on liver and kidney functions in adult rats and potential protective effect of vitamins $\mathrm{C}$ and E. Food and Nutrition Sciences, 2012.

29. Ortiz, G. G., Bitzer-Quintero, O. K., Zárate, C. B., Rodríguez-Reynoso, S., Larios-Arceo, F., VelázquezBrizuela, I. E., ... \& Rosales-Corral, S. A. (2006). Monosodium glutamate-induced damage in liver and kidney: a morphological and biochemical approach. Biomedicine \& pharmacotherapy, 60(2), 86-91. 
30. Sakr, S. A., \& Badawy, G. M. (2013). Protective effect of curcumin on monosodium glutamate-induced reproductive toxicity in male albino rats. Global J Pharmacol, 7, 416422.

31. Roa, I., \& del Sol, M. (2020). Monosodium Glutamate Alters the Function and Morphology of the Parotid Gland in Sprague Dawley Rats. International Journal of Morphology, 38(4).

32. Mahmoud, E. F., Mahmoud, M. F., \& Hegazy, E. (2020). Chitosan Nanoparticles Suppress The Oxidative Stress in Submandibular Salivary Glands and Prevent The Genotoxicity of Monosodium Glutamate In Albino Rats: Histological, Immunohistochemical and Chromosomal Aberrations Analysis Study. Egyptian Dental Journal, 64(4-October (Oral Medicine, X-Ray, Oral Biology \& Oral Pathology)), 3485-3498.

33. Shredah, M. T., \& Nagy, D. A. (2017). Effect of Monosodium Glutamate on the Sublingual Salivary Glands of Rats (Histological And Histochemical Study). Egyptian Dental Journal, 63(4-October (Oral Medicine, X-Ray, Oral Biology \& Oral Pathology)), 3263-3270.

34. Soliman, A. M. (2011). Extract of Coelatura aegyptiaca, a freshwater clam, ameliorates hepatic oxidative stress induced by monosodium glutamate in rats. African Journal of Pharmacy and Pharmacology, 5(3), 398-408.

35. LEE, D. Y., CHOI, I. S., HAN, J. H., \& YOO, H. S. (2002). Chitosan and D-glucosamine induce expression of Th1 cytokine genes in porcine spleen cells. Journal of veterinary medical science, 64(7), 645-648.

36. Mori, A., Oleszycka, E., Sharp, F. A., Coleman, M., Ozasa, Y., Singh, M., ... \& Lavelle, E. C. (2012). The vaccine adjuvant alum inhibits IL-12 by promoting PI 3 kinase signaling while chitosan does not inhibit IL-12 and enhances T h1 and T h17 responses. European journal of immunology, 42(10), 2709-2719.

37. Quan, H., Zhu, F., Han, X., Xu, Z., Zhao, Y., \& Miao, Z. (2009). Mechanism of anti-angiogenic activities of chitooligosaccharides may be through inhibiting heparanase activity. Medical hypotheses, 73(2), 205-206.

38. Onyema, O.,Aisil, C. and Ihetuge, A. (2012). Monosodium glutamate induces oxidative stress and affects glucose metabolism in the kidney of rats. Int. J. Biochem. Res. Rev., 2: 1-11.

39. Kumar, P. and Bhandari, U . (2013). Protective effect of Trigonella foenum-graecum Linn. on monosodium glutamate-induced dyslipidemia and oxidative stress in rats. Indian J. Pharmacol., 45: 136140.

40. Manikandana, P., Sumitra, M., Aishwarya, S., Manohar, B., Lokanadam, B. and Puvanakrishnan, R. (2004). Curcumin modulates free radical quenching in myocardial ischaemia in rats. Int. J. Biochem. Cell Biol., 36: 1967-1980.

41. Chan, W. and Yu,J. (2006). Curcumin inhibit UV irradiation induced oxidative stress and apoptotic biochemical changes in human epidermoid carcinoma AA31 cells. J. cellular Biochemistry, 90: 327-338.

42. Feng, J., Tao, T., Yan, W., Chen, C. S., \& Qin, X. (2014). Curcumin inhibits mitochondrial injury and apoptosis from the early stage in EAE mice. Oxidative medicine and cellular longevity, 2014.

43. Qin, X., Cao, M., Lai, F., Yang, F., Ge, W., Zhang, X., ... \& Li, L. (2015). Oxidative stress induced by zearalenone in porcine granulosa cells and its rescue by curcumin in vitro. PloS one, 10(6), e0127551. 